\title{
147. Triploidy appeared in the Back-Cross Offspring from Funa-Carp Crossing
}

\author{
By Yoshio OJima,*) Makoto Hayashi,*) and Koichi UEno**) \\ (Comm. by Sajiro Makino, M. J. A., Oct. 13, 1975)
}

Although a considerable work has so far been done on fish hybrids by a number of ichthyologists in both scientific and practical interest, knowledge has remained meagre on the cytogenetic problems. Analyses of genetic systems by means of experimental hybridization have proved important for the understanding of cytotaxonomic difference of related forms. On the other hand, significant co-relationships between the geographical distribution and chromosomal polymorphism or polyploidism have been announced in fishes. Importance of experimental hybridization in fishes has been increasing for the critical consideration of species differentiation.

The genus Carassius known by a common name of the Funa is a member of the Cyprinidae distributing in Japan, and subdivided into 5 subspecies according to Nakamura (1969): Carassius auratus subsp.; C. a. buergeri; C. a. grandoculis; C. a. langsdorfii; and C. a. cuvieri. Two types of reproduction have been suggested in these subspecies: bisexual and gynogenesis. Kobayashi (1970, 1972, 1973) reported three chromosomal polymorphisms characterized by diploid, triploid and tetraploid forms in C. a. langsdorfii. Diploid and triploid forms have been noted in $C$. a. buergeri (Kobayashi 1975). It has been shown that in gynogenetic forms, triploid eggs are activated by sperm from bisexual species, and that the paternal genome does not participate in the fertilization. Then the offspring possess the maternal genome only.

Implicated in speciation, polyploidism and reproduction of the genus Carassius, the present authors have been dealing with some cytogenetic investigations in intergeneric hybrids between the Funa (Carassius auratus cuvieri) and the Carp (Cyprinus carpio) produced by experimental way.

Materials and methods. When kept under a confined condition, the Funa (우) and the Carp (令) mated and produced hybrids $\left(F_{1}\right)$. Reciprocal crosses were also possible with similar results. The hy-

*) Department of Biology, Kwansei Gakuin University, Nishinomiya.

**) Department of Fishery, Kinki University, Higashi-Osaka.

Reprint request: Dr. Y. Ojima, Dept. of Biology, Faculty of Science, Kwansei Gakuin University, Nishinomiya, 662 Japan. 
brids grew rather rapidly showing no observable abnormalities. The egg-cleavage proceeded without mitotic disturbance. The breeding experiments by Ojima since 1945 resulted in that the hybrid males were completely sterile. It has recently been shown by Ojima that $F_{1}$ females laid eggs in back-crossing with the Carp, and that they developed into adults without any visible abnormality. The present chromosome study was made on the Funa (C. a. cuvieri), the Carp (Cyprinus carpio), $\mathrm{F}_{1}$ (Funa ㅇ $\times$ Carp $\hat{\text { o) }}$ ), and back-cross offspring $\left(\mathrm{F}_{1}\right.$ 우 $\times$ Carp $\left.\hat{0}\right)$.

Kidney tissues were removed, minced with scissors and suspended in fish-BSS. They were treated with colchicine $(0.5 \mu \mathrm{g} / \mathrm{ml})$ for 30 minutes at room temperature. Following KCl-hypotonization $(0.075 \mathrm{M})$ for $15-20$ minutes, and Carnoy-fixation as usual, slides were air-dried and Giemsa-stained.

Results and remarks. Details of the chromosome morphology of the Funa (Carassius auratus cuvieri) and the Carp (Cyprinus carpio) were given in the former papers (Ojima et al. 1966, 1967). It was shown that the Carp and the Funa had 100 chromosomes in the diploid complement. Morphologically the chromosomes showed
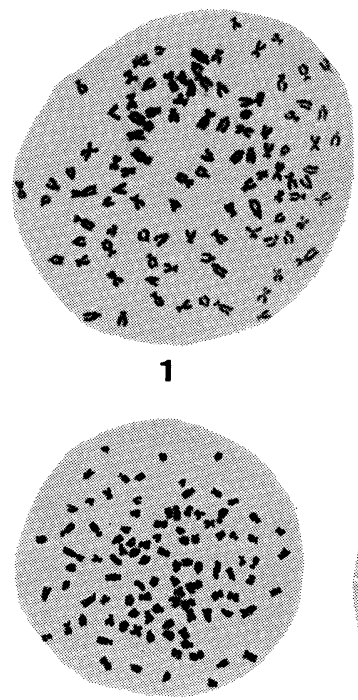

4

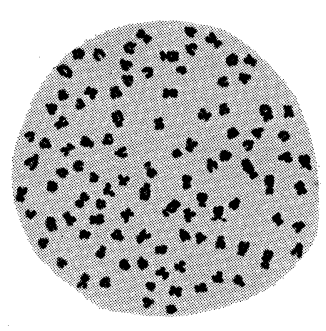

2

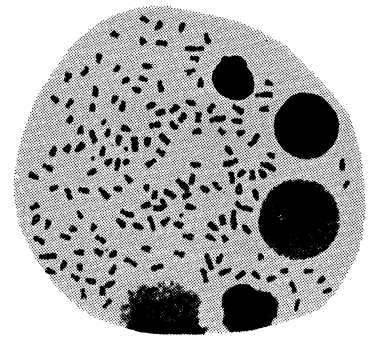

5

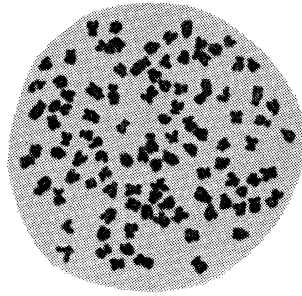

3

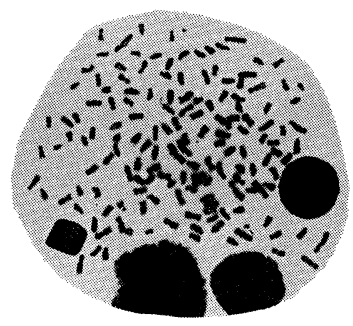

6

Figs. 1-6. Metaphase chromosomes of the Funa, Carp, $F_{1}$ hybrids and back-cross offspring. Fig. 1: The Funa. 2n, 100. Fig. 2: The Carp. 2n, 100. Fig. 3: The $F_{1} .2 n, 100$. Fig. 4: Diploid back-cross individual. 2n, 100. Fig. 5: Triploid-range chromosomes of a triploid back-cross individual. 3n, 156. Fig. 6: The same of a back-cross individual. 3n, 155. 


\section{$282288 \times 88484$}

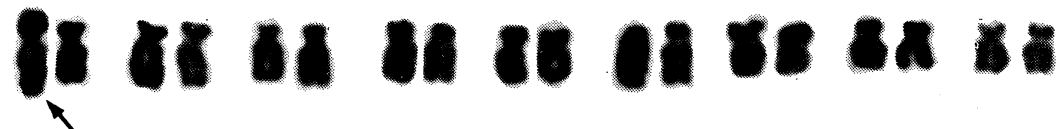

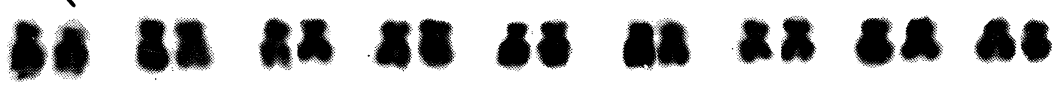

10 an a

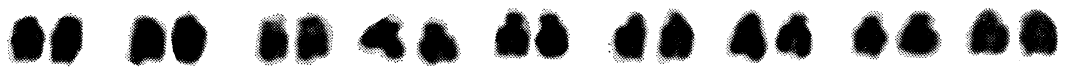

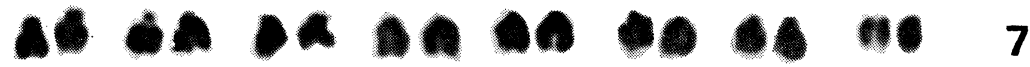

Fig. 7. Karyotype of the $F_{1}$ with 100 chromosomes. Arrow shows the largest submetacentric chromosome originated from the Funa.

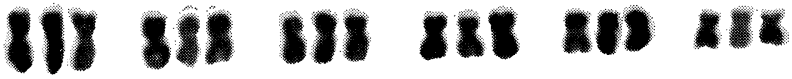

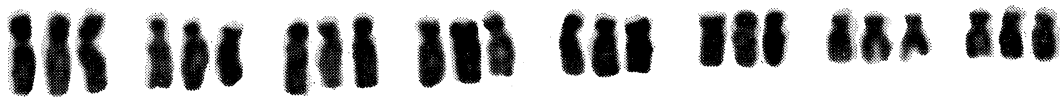

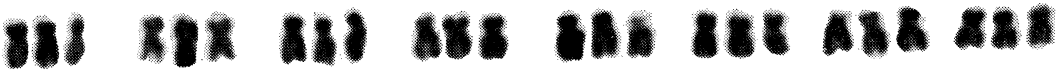

\section{Dab ub hă axo}

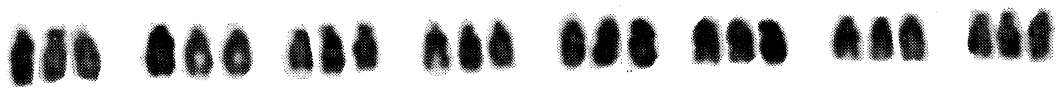

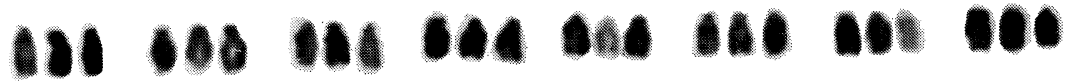

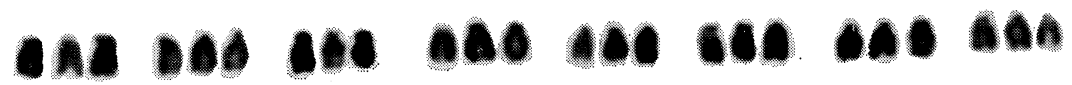

- - - *

Fig. 8. Karyotype of a 3n-range cell from a triploid back-cross specimen. 3n, 156.

no appreciable difference between the two forms, except the largest submetacentric pair (Figs. 1-2). It is natural to speculate that the $F_{1}$ offspring between the Funa (우) and the Carp (令) have 100 
chromosomes in $2 \mathrm{n}$. Then, the chromosome counting of the $\mathrm{F}_{1}$ offspring showed 100 chromosomes in diploid (Fig. 3). Karyotypically the $\mathrm{F}_{1}$ chromosomes did not differ from those of the parent species. The diploid complement was characterized by 6 pairs of relatively metacentrics, 18 pairs of mostly submetacentrics and 26 pairs of acrocentric or telocentrics, except the largest submetacentric chromosome which originated from the Funa (Fig. 7, by arrow). Evidently the $F_{1}$ chromosomes, 100 in number, are a total sum of the haploid set of the parent species.

The author's experiments (Ojima et al. 1961) resulted in that the $F_{1}$ males were completely sterile, while the females were capable of laying eggs. Theoretically, the back-cross individuals between the $\mathrm{F}_{1}$ female and the male Carp should have 100 chromosomes in diploid. Opposed to this assumption, the back-cross offspring having a $3 \mathrm{n}$ range chromosome complement appeared in one half of the progenies. The chromosome number of the diploid back-cross offspring was 100 (Fig. 4) which consisted of 6 pairs of metacentrics, 21 pairs of submetacentrics, and 23 pairs of telo- and acrocentrics.

The chromosomes of the triploid back-cross offspring were 145 to 160 in number. The karyotype of the 156-chromosome cells provided an evidence of the trisomic condition for the meta- and submetacentric chromosomes which were morphologically well-defined, though no informative feature was obtained for the telo- and acrocentric chromosomes on account of the paucity of characteristic configuration for analysis (Fig. 8). Noticeable is the occurrence of minute elements, or microchromosomes, in some of the 3n-range metaphases of the back-cross individuals.

The significance of triploidy has remained unclear in the course of evolution of the Funa. The occurrence of 3n-range back-cross specimens seems to throw some light on the differentiation of species in the Funa. Further, interesting are the facts that the most individuals showing the 3n-range chromosomes were females, and that they showed an inter-chromosomal variation similar to the findings in Carassius a. langsdorfii by Muramoto (1975). Further information and discussion on the significance of triploidy will be available in the near future, since crossing experiments have been in progress.

Summary. A chromosome study is made on the Funa, the Carp, $\mathrm{F}_{1}$, and back-cross individuals $\left(\mathrm{F}_{1}\right.$ 우 $\times$ Carp $\left.\hat{\delta}\right)$. The occurrence of triploidy in the female back-cross offspring is noted. The significance of triploidy is discussed in relation to the differentiation of species in the Funa.

Acknowledgments. The authors are grateful to Dr. S. Makino, M. J. A., Professor Emeritus, Chromosome Research Unit, Hokkaido 
University, for going over the manuscript and for invaluable advices. The author's thanks are also due to Dr. A. Hamaguchi and Mr. S. Shibata, Hyogo Fisheries Research Station, for the facility of breeding fishes used.

\section{References}

Kobayashi, H., Y. Kawashima, and N. Takeuchi (1970) : Japan. Jour. Ichthyol., 17, 153-160.

Kobayashi, H., and N. Ochi (1972): Zool. Mag. (Tokyo), 81, 67-71.

Kobayashi, H., N. Ochi, and N. Takeuchi (1973): Japan. Jour. Ichthyol., 20, $7-12$.

Kobayashi, H. (1974) : Ichthyol. Soci. of Japan.

Muramoto, J. (1975) : Proc. Japan Acad., 51, 583-587.

Nakamura, N. (1969) : Cont. from the Res. Inst. for Natural Resources, No. 1198.

Ojima, Y., S. Takayama, M. Kusa, and A. Hamaguchi (1961): Zool. Mag. (Tokyo), 70, 243-247.

Ojima, Y., S. Hitotsumachi, and S. Makino (1966) : Proc. Japan Acad., 42, 62-66.

Ojima, Y., and S. Hitotsumachi (1967) : Japan. Jour. Genet., 42, 163-167. 